\title{
ITW Dynatec receives the IDEA Achievement Award
}

\begin{abstract}
A t the International Engineered Fabrics Conference \& Expo (IDEA), ITW Dynatec took home its second consecutive "Most Innovative Technology" award.

ITW Dynatec's Surge technology won this top honour in the IDEA Achievement Awards category, sponsored by INDA (the Association of the Nonwovens Fabrics Industry).

The key feature of the award-winning Surge application method is the combination of application weights. For the first time, this gives users the option of applying different weights of adhesive on the same substrate.

The benefits include significant reductions in adhesive use and in the amount of waste produced, together with improved productivity.
\end{abstract}

For more information: ITW Dynatec, Tel.: +1 800966 6358, info@itwdynatec.com, www.itwdynatec.com

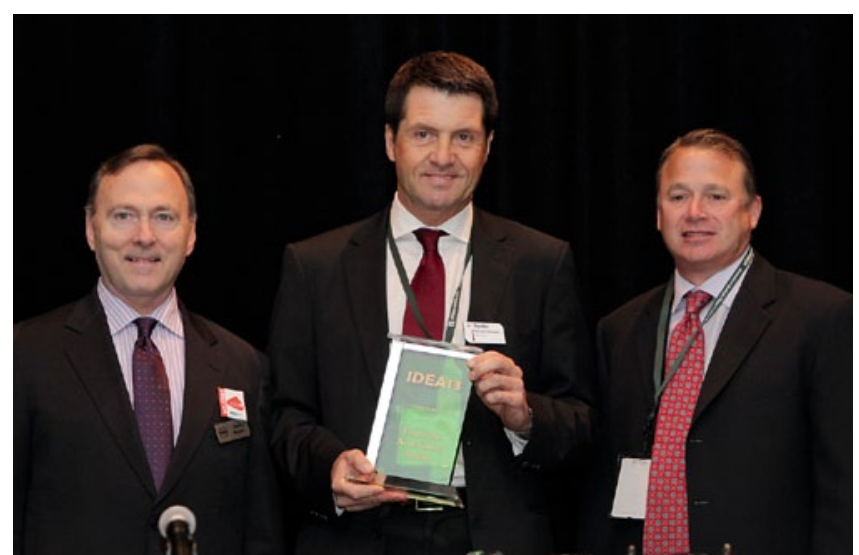

"It is so rewarding to see that our efforts are bringing real added value for our customers," said Christof Schotten, vice president/ general manager (centre) of ITW Dynatec after the award ceremony at IDEA 2013 in Miami.

\section{Plasmatreat US continues to expand}

$\Lambda$ s part of its expansion on the AmerAican market, Plasmatreat US LP, a subsidiary of the German company Plasmatreat $\mathrm{GmbH}$, has acquired 4th State, Inc., a Californian company specialising in low-pressure plasma. Plastmatreat US began its move into the low-pressure plasma market by purchasing Plasma Technology Systems LLC at the end of 2011.

4th State focuses primarily on hightech contract services for customers' components. Included in the takeover is 4th State's customer base, which consists of medical, aerospace and electronics companies.

One of the company's main treatment facilities is a 1.5-metre-wide, continuous roll-to-roll plasma chamber designed by

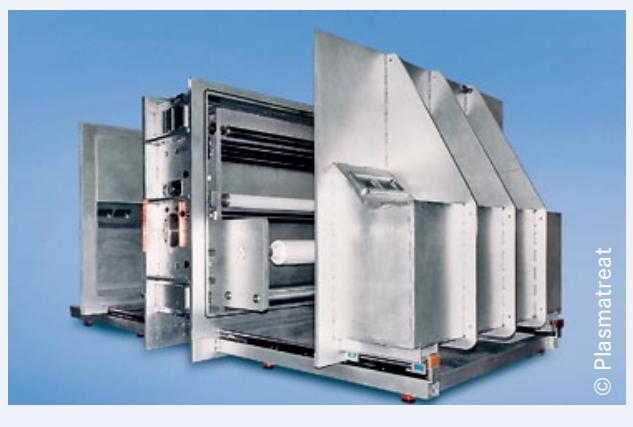

Surfaces of rolled goods with a width of up to $1.5 \mathrm{~m}$ can be treated with this lowpressure plasma system. the US polymer chemist Stephen Kaplan. Its function is the plasma modification of wide rolled goods, including wovens, non-wovens, films, foils and membranes, which are bonded, printed or coated in subsequent processes
The three companies plan to come together under one roof at new premises in the San Francisco Bay area in the autumn of this year.

For more information: www.plasmatreat.de

\section{BASF and Sinopec intensify their cooperation}

B ASF and Sinopec are considering extending their 50-50 joint venture BASF-YPC Company Limited in Nanjing in China, which was founded in 2000, with the expansion of existing ethylene ox- ide (EO) production and the construction of a new plant for neopentylglycol (NPG). In addition, BASF-YPC will further expand its acrylic acid value chain with additional acrylic acid and butyl acrylate plants. Production is expected to begin in 2014. Acrylic acid is an important precursor for the production of superabsorbent polymers. Butyl acrylate, one of the esters of acrylic acid, is used to manufacture adhesives and paints. 